\title{
Physical Discomfort May Be Reduced in the Presence of Interior Plants
}

Virginia I. L ohr ${ }^{1}$ and Caroline H . Pearson-M ims ${ }^{2}$

AdDitionAl INDEX WORDs. benefits of plants, emotional responses, foliage plants, human-horticulture relationships, human issues in horticulture, human wellbeing, pain, people-plant interactions, response to nature, room assessment

Summary. A well-known research report showed that being in a hospital room with a view of trees rather than a view of a building was linked to the use of fewer pain-reducing medications by patients recovering from surgery. The experiment reported here was designed to further examine the role of plants in pain perception. We found that more subjects were willing to keep a hand submerged in ice water for 5 min if they were in a room with plants present than if they were in a room without plants. This was found to be true even when the room without plants had other colorful objects that might help the subject focus on something other than the discomfort. R esults from a room assessment survey confirmed that the room with colorful, nonplant objects was as interesting and colorful as the room with plants present, but the presence of plants was perceived as making the air in the room fresher.

hroughout history, people have benefited from interactions with plants. People customarily give flowers to the ill, and people report feeling happier in the presence of plants. M any hospitals include gardens and therapeutic programs using plants as part of their treatment plans. Studies have shown that people also benefit when exposed to plants in passive situations, such as simply viewing live plants or pictures of plants (U Irich and Parsons, 1992).

Research is beginning to show that responses to plants can be linked directly to improved health. O ne study demonstrated that prison inmates who viewed nature had a lower rate of reporting to sick call compared with inmates who viewed the interior of the prison (M oore, 1981-82).

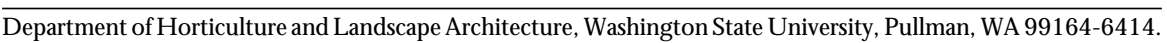

This research protocol was reviewed and approved by the WSU H uman Subjects I nstitutional Review Board. The authors express appreciation to J. Richard Alldredge, Professor in Statistics, Washington State U niversity, for statistical support. The authors express appreciation for the financial support of the American Floral Endowment. The cost of publishing this paper was defrayed in part by the payment of page charges. U nder postal regulations, this paper therefore must be hereby marked advertisement solely to indicate this fact.

1Professor.

${ }^{2}$ Research technologist. 
In another study, hospital patients who viewed plants from their windows recovered more quickly from surgery than patients who viewed a building (U Irich, 1984). M ore recently, research with cancer and Alzheimer patients has
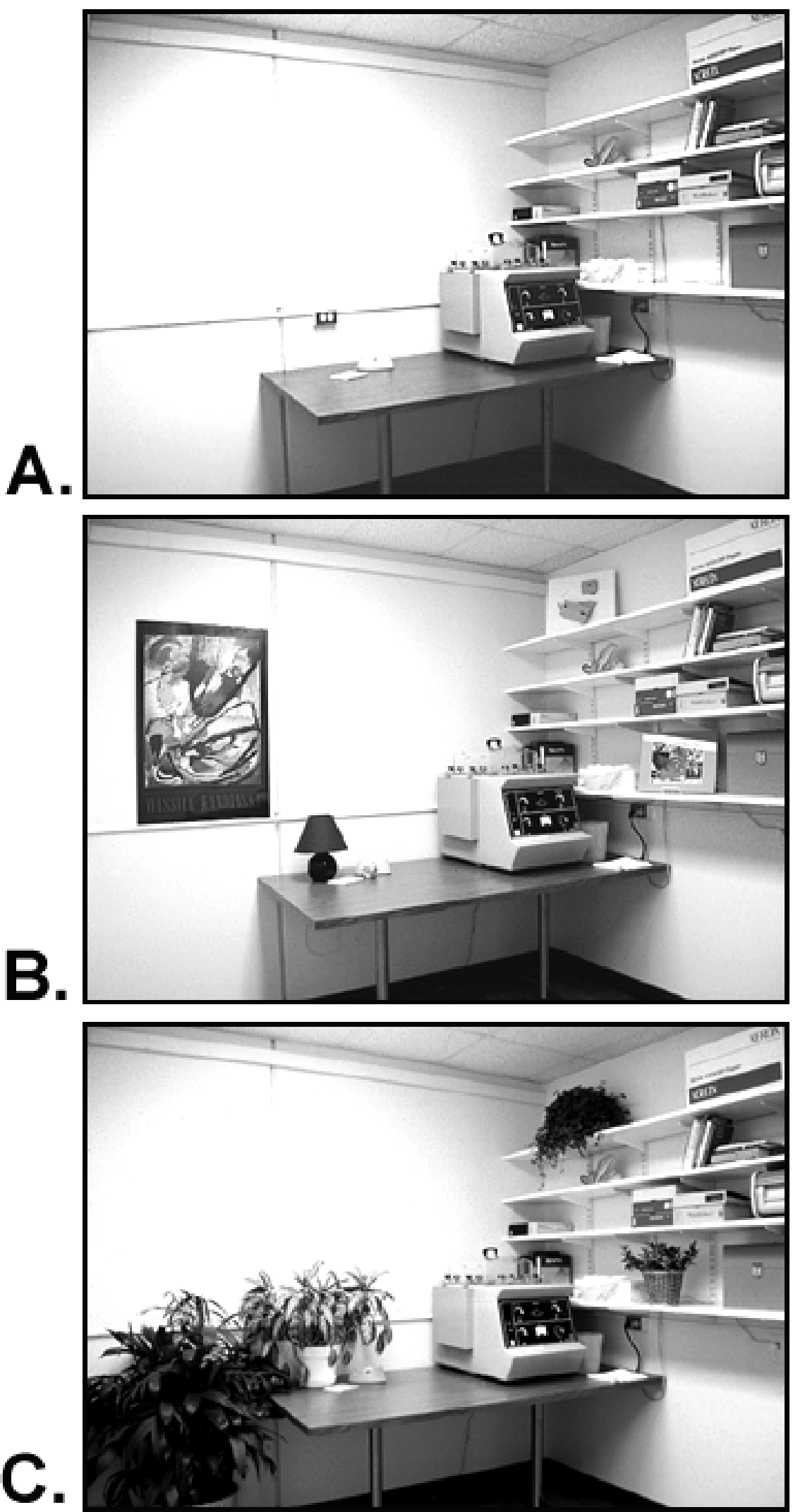

Fig. 1. Subjects were tested in three different interior room treatments: (A) control, (B) nonplant objects, and (C) plants.

shown walking in agarden to be restorative (Cimprich, 1993; Mooney and Nicell, 1992).

O ther research hasshown that more complete recovery from stress can also occur in peopleworking in rooms decorated with interior plants (Lohr et al., 1996). O ne of these studies demonstrated aspecific link between plantsand pain response in people (U Irich, 1984). It reported that patients with a view of trees from their hospital windows used fewer potent pain-relieving drugs than did patients with a view of a brick wall. $M$ ore research is needed to confirm this link to pain perception and to clarify the magnitudeand breadth of thisresponse.

This study was designed to examine further the ability of the presence of plants to relieve people's perceptions of pain or to increase people'stolerance of pain. The specific objective of this research wasto determineif healthy adults who passively view interior plantsunder controlled conditions will tolerate experimentally induced physical discomfort (acute pain) longer than individuals in settings without plants. Acute pain was selected for this study, because it can be readily controlled in a laboratory setting, and it does not cause excessive discomfort for the subjects. The cold pressor method, one of the most widely used experimental pain-induction methods, was used; it involves placing the subject's hand in ice water for a brief period (Wolff, 1986). If being around plants can help people feel less pain or tolerate pain longer in an experimental setting, then these results may be applied to clinical settings, such as health care facilities, as well.

\section{Materials and methods}

EXPERIMENTAL SETting. The experimental room was $3.5 \mathrm{~m}$ (11.5 ft) long, $6 \mathrm{~m}(20 \mathrm{ft})$ wide, and $2.4 \mathrm{~m}(8 \mathrm{ft})$ high. The walls were an off-white color. The room had no windows and was illuminated with overhead fluorescent lights. The conditionsin theroom averaged 23 ${ }^{\circ} \mathrm{C}\left(73^{\circ} \mathrm{F}\right), 34 \%$ relative humidity, and $703 \mathrm{~lx}(70 \mathrm{fc})$ where the subject was seated during the experimental treatments.

TreatMents. Subjects were tested in three different interior room treatments: control, nonplant objects, and plants. The same room was used for the three treatments: plants or nonplant objectswereadded or removed asneeded to achieve each treatment. For the control, the room was designed to repre- 
T able 1. Interior plants and corresponding decorative, nonplant objects added to the experimental room during trials when additional stimuli were present.

\begin{tabular}{|c|c|c|c|c|}
\hline \multirow{2}{*}{$\begin{array}{l}\text { Common } \\
\text { name }\end{array}$} & \multirow[b]{2}{*}{ Species } & \multicolumn{2}{|c|}{$\begin{array}{l}\text { Container } \\
\text { size }\end{array}$} & \multirow{2}{*}{$\begin{array}{l}\text { Nonplant } \\
\text { object }\end{array}$} \\
\hline & & $(\mathrm{cm})$ & (inches) & \\
\hline Chinese evergreen & A glaonema Schott & 15 & 6 & T ablelamp and paperweight \\
\hline Bamboo palm & Chamaedorea seifrizii Burret & 20 & 8 & Abstract art poster \\
\hline H eart-leaf philodendron & $\begin{array}{l}\text { Philodendron scandens K. Koch \& Sello var. } \\
\text { oxycardium (Schott) Bunting }\end{array}$ & 10 & 4 & Weather station \\
\hline
\end{tabular}

sent a typical office space (Fig. 1A). It contained conventional office furniture and suppliesand theexperimental equipment needed for this study. For the nonplant objects treatment, decorative and colorful items, including abstract art posters and a small table lamp, were added to the control room (Fig. 1B). For the plants treatment, interior plants were added to the control room (Fig. 1C). I tems of similar size and impact were placed in similar locations in the nonplant objects and plants treatments (Table 1). The nonplant objects treatment was designed to be as visually interesting and colorful as the plants treatment, so that the effects of plantsas simply a mental diversion from a dull room could be assessed. Each subject was randomly assigned to one treatment and was tested individually.

Subj Ects. Adults from the local and university communities were solicited for thisstudy. Each subject was paid $\$ 10$ for participating in the experiment. A total of 198 subjects completed the experiment (67 in the control treatment, 62 in the nonplant objects treatment, and 69 in the plants treatment). Thirty-six percent of the subjects were male and 64\%werefemale; 84\%were 24 years old or younger; and $89 \%$ of the subjects were university students, while $11 \%$ wereuniversity employeesor members of surrounding communities. When asked if they liked plants, $90 \%$ said "yes" and the remainder had either no opinion or said "no;" $59 \%$ owned plants. There were no significant differences among the treatment groups for these characteristics.

Variables measured. A demographic questionnaire was developed to obtain information from the subjects about factors such as their gender, age, and self-described ability to toleratepain.

A room assessment survey was designed to evaluate the subject's initial impressions of the experimental space. Thesurvey was developed and pretested after reviewing a similar environmental assessment by other researchers (Rohles and M illiken, 1981). Respondentswere asked to judge their perceptions of the room against 17 polar opposite pairs of terms or phrases, using a Semantic $D$ ifferential Scale (Anderson, 1987). The order of thetermsor phrasesin each pair was randomized. Each pair was scored from 1 to 5 , with a rating of 1 most associated with the more negative characteristic in the pair and 5 most associated with theother paired characteristic.

Physiological responsesweremonitored by recording skin temperature and blood pressure. The subject's skin temperaturewasmonitored using adigital thermometer (model 61220-670; VWR Scientific Products Corp., Seattle, Wash.) equipped with a skin temperature probe (YSI 409B; Yellow Springs Instrument $\mathrm{Co}$., Inc., Yellow Springs, O hio). The probewastaped to theupper surface of the dominant hand. The subject's blood pressure was measured using an automatic oscillometric digital blood pressure monitor (model H EM -713C; O mron H ealthcare, Inc., Vernon H ills, III.). Thecuff of themonitor was placed on the subject's nondominant arm, so that readings could betaken whilethe dominant hand was being used to complete the surveys and skin temperature also could be monitored. Subjectswereasked to place the cuffed arm in a stationary and relaxed position during themeasurements.

Subjects' emotional states were measured by a modified version of the self-report Zuckerman Inventory of Personal Reactions (ZIPERS) (Zuckerman, 1977). M odifications included clarifying some of the wording and shortening the survey by one statement. R espondentsindicated, on a scale from 1 to 5 , the degree to which each statement, such as "I feel sad," described the way they felt at that moment.

Thelevel of discomfort (pain toler- ance) was measured by recording whether subjects held their hands in ice water for a full $5 \mathrm{~min}$. Procedures for measuring this variable are described below.

Procedures. U pon entering the experimental room, subjects weregiven time to desensitize from the outside environment and become accustomed to the room's decor. During this time, subjects received general instructions about the experiment. The skin temperature monitor and blood pressure cuff were placed on the subject. The demographic questionnaire, room assessment survey, and the ZIPERS were also administered. When 10 min of the desensitizing period had elapsed, blood pressure and skin temperature were recorded.

Following the desensitizing period, subjects immersed their nondominant hands for 2 min in a warm water bath $\left[37^{\circ} \mathrm{C}\left(98.6^{\circ} \mathrm{F}\right)\right]$. Thewarm water bath was maintained at normal body temperatureto ensurethat all subjects' hands were at a similar temperature prior to placement in the ice water bath and to sensitize their hands for the ice water. Subjects were then instructed to immersetheir handsup to their wristsin an ice water bath (Wolff, 1986) and to keep their hands in the ice water until "you feel uncomfortable." They were reminded that they could remove their handsfrom theice water at any time. We limited the maximum length of the ice water immersion to $5 \mathrm{~min}$ for the comfort of the subject and to prevent the hand from becoming numb. Subjects were told that the water bath would be monitored to prevent any harm to their hands, but were not told of the 5-min time limit.

Skin temperatures of the nonimmersed hands were measured whilethesubjects' handswereimmersed in icewater. After removing their hands from the ice water bath, the subjects completed aposttest ZIPERS, and their 
skin temperatures and blood pressures were again measured.

Statistical analyses. D ata for subjects tested in the presence of plants were compared to those for subjects tested in the control and nonplant objects rooms.

N oncontinuousdata (room assessment, ZIPERS, and pain tolerance) were analyzed in a two-step procedure. The first step looked for differences among the treatments. If significant differences were detected, then the second step was implemented to maketwo specific comparisons among the treatments: plants compared to the control and plants compared to nonplant objects. When the noncontinuous data had more than two response categories possible (room assessment and ZIPERS), we used the Kruskal-Wallis test in the N PAR IWAY procedurein SAS to obtain achi-square statistic for the first step (SAS I nstitute Inc., 1988). The multiple comparisons procedure of Conover (1980) wasused to compare differencesamong thethree treatments for the second step. Pain tolerance data had only two categories and were analyzed first via two-way chisquare contingency tables from the FREQ procedure in SAS (SASI Institute Inc., 1988). These data were subsequently analyzed using two-way chisquare contingency tables for reduced treatment data sets for Step 2.

Continuous data (physiological measures) wereanalyzed using the G L M procedure in SAS (SAS Institute I nc., 1988), with contrast statementsto make the same two specific comparisons among thetreatmentsmentioned above: plants compared to the control and plants compared to nonplant objects.

$D$ ifferent alpha levels were set for different parts of this experiment, depending on the variable, to ensure that important relationships would not be overlooked. For most of the results, an alpha level of $10 \%$ was set. For the emotional state data (ZIPERS), an alphalevel of $15 \%$ wasset, becausepeople's emotional states can be highly influenced by conditions outside of the experiment. For the pain tolerance variable, the alpha level was set at $5 \%$ because it is important to be cautiousin interpreting this important potential impact of plants on people.

For the room assessment data, the characteristics "fresh air" and "calming" were significant at the $10 \%$ level in Step 1. At the $5 \%$ level in Step 1, the following room assessment characteris- tics were significant: "interesting," "cheerful," "colorful," " pleasant," " attractive," " safe," " comfortable," " inviting," "ornate," and "tasteful." These room assessment characteristics were analyzed further in Step 2.

For the ZIPERS data, the following statementsweresignificantatthe15\%level in Step 1: "carefree or playful," "friendly or affectionate" (both beforeicewater), and "happyor pleased" (after icewater). "Fearful" (before ice water) and "my heart is beating fast" (after ice water) were significant at the $10 \%$ level in Step 1. These ZI PE RS statements were analyzed further in Step 2.

Pain tolerance data were significant at the $5 \%$ level in thefirst step of the analysis. These data were subsequently analyzed in Step 2.

Responses on the demographic survey wereexamined using theK ruskalWallis test in the N PARIWAY procedure in SAS (SAS I nstitute I nc., 1988) to look for differences by treatment assignment. To examine whether a demographic variable helped explain the subjects' responses on the pain tolerance variable, we used the CATM OD procedure in SAS to look for a significant interaction between the demographic variable and treatment.

\section{Results and discussion}

Demographics. There were no significant relationships between any of the demographic survey variables and treatment, except for physical health. About $71 \%$ of the subjects in the room with plants reported their overall physical health as above average to excellent, while only $52 \%$ of those in the control room and $56 \%$ of those in the nonplant objects room described their physical health as such. Statistics examining the treatment by demographic responsefor this variable and others that might have explained the results also were examined, and no significant or meaningful relationships were found. For example, people's self-described ability to tolerate pain did not influence how they responded to the treatments. Similarly, whether they owned or liked plants did not influencetheir responseto thetreatments. These analyses confirmed that there were no meaningful differences among subjectsin the treatment groups and that thedemographic variableswere not useful in interpreting the results. For this reason, only the results for all subjects within a treatment will be reported, and the statistics for responses will not be categorized based on demographic responses.

Room ASSESSMENT. The room with plants present was rated significantly differently from the control treatment on 12 of the 17 characteristics(T able2). When plants were present, the room was more associated with positive characteristics, such as "cheerful," "calming," and "attractive," on most of the descriptivescalesthan thecontrol room. These results are consistent with the findings of other researchers who have shown apositiveattitudetowardsrooms with plants ( $L$ arsen et al., 1998; L aviana et al., 1983; Shoemaker et al., 1992).

When the room with plants was compared to thenonplant objectsroom, theplants treatment still was rated more positively, but the difference between the two treatments was not as great (Table2). In thiscomparison, theplants room was rated as more associated with positive attributes on 6 of the 17 descriptive scales. A comparison of the specific features indicates that the nonplant objectstreatment wascomparable to the plants treatment on visual characteristics, including "interesting," "colorful," and "ornate." Thisindicated that the nonplant objects treatment was an effective comparison room to the plants treatment, since both rooms would provide a comparable level of mental interest compared to the dull control room. Theplantstreatment was significantly different from thenonplant objects treatment on other variables that indicate other positive contributionsof plants, including "fresh air" and "calming."

Physiological measures. There were no significant differences in the subjects' blood pressures or skin temperatures(datanot shown) among treatments at any time during the experiment. Peoplein all treatments had similar blood pressureand skin temperaturereadings before the cold pressor was administered, and there was little change in these measures during the course of the experiment. Skin temperature decreased slightly in all treatments while the unmeasured hand was held in ice water. Prior to submerging their handsin icewater, the average blood pressure for all subjects was 117/ 75 and the average skin temperature was $84^{\circ} \mathrm{F}\left(29^{\circ} \mathrm{C}\right)$.

Emotional state. Before the cold pressor was administered, there were significant differences for the ZIPERS responses for people tested in the presence of plants compared to those in the 
Table 2. Subjects' assessments ${ }^{2}$ of the experimental room with no decorative objects present (control) or with nonplant decorative objects compared to subjects' assessments with plants present.

\begin{tabular}{|c|c|c|c|}
\hline Room characteristic & Control & N onplant objects & Plants \\
\hline boring . . . . . interesting & $2.49^{*}$ & $3.13^{\mathrm{NS}}$ & 2.94 \\
\hline gloomy..... cheerful & $2.54^{*}$ & $2.98^{y}$ & 3.23 \\
\hline stale air ..... fresh air & $2.97^{*}$ & $2.90^{*}$ & 3.26 \\
\hline crowded ..... . uncrowded & $3.88^{\mathrm{NS}}$ & $3.69^{\mathrm{NS}}$ & 3.55 \\
\hline drab or dull . . . . colorful & $1.72^{*}$ & $2.82^{\mathrm{NS}}$ & 2.81 \\
\hline hectic ..... calming & $3.27^{*}$ & $3.42^{y}$ & 3.59 \\
\hline unpleasant ..... . pleasant & $3.07^{*}$ & $3.23^{*}$ & 3.54 \\
\hline noisy .... . quiet & $2.82^{\mathrm{NS}}$ & $2.90^{\mathrm{NS}}$ & 3.10 \\
\hline confined ..... spacious & $2.22^{\mathrm{NS}}$ & $2.42^{\mathrm{NS}}$ & 2.51 \\
\hline ugly ..... attractive & $2.30^{*}$ & $2.71^{\mathrm{NS}}$ & 2.83 \\
\hline frightening . . . . . safe & $3.69^{*}$ & $3.92^{\mathrm{NS}}$ & 4.04 \\
\hline uncomfortable ...... comfortable & $3.18^{*}$ & $3.56^{\mathrm{NS}}$ & 3.58 \\
\hline drafty.... . still & $3.79^{\mathrm{NS}}$ & $3.63^{\mathrm{NS}}$ & 3.58 \\
\hline messy ..... neat & $3.81^{\mathrm{NS}}$ & $3.56^{\mathrm{NS}}$ & 3.81 \\
\hline uninviting . . . . . inviting & $2.37^{*}$ & $2.87^{*}$ & 3.19 \\
\hline plain ..... ornate & $1.54^{*}$ & $2.18^{\mathrm{NS}}$ & 2.16 \\
\hline tacky . . . . . tasteful & $2.85^{*}$ & $3.02^{*}$ & 3.42 \\
\hline
\end{tabular}

${ }^{\mathrm{z}} \mathrm{M}$ eans are based on a scale of 1-5, with 1 most associated with the first term in the pair and 5 most associated with the second term in the pair.

$\mathrm{NS}, \mathrm{y},{ }^{*}$ Score is nonsignificant (NS) or significantly different from score with plants at $\mathrm{P} \leq 0.10$ (y) or $0.05(*)$, respectively.

control and nonplant objects rooms (Table 3). People in the room with plants generally reported higher levels of positive emotions, such as feeling carefree or friendly, than those in the control or nonplant objects rooms. These results are similar to those found for the room assessment in this study and in other studies (Laviana et al., 1983). At the start of an experiment, subjects are probably feeling apprehensive about what will actually occur during the experiment; perhaps they feel thismorestrongly when theexperiment is conducted in a room without plants than in aroom with plants. Thispositive emotional response to the presence of plants was not found in astudy by L ohr et al. (1996) and the response was weak in thestudy by Shoemaker et al. (1992); reasonsfor variations in this response in different studies may require further investigation.

Before placing their hands in ice water, peoplein all treatments generally reported low levels of negative emotions, such as feeling sad or feeling like hurting someone (Table 3). O ne negativeemotion, feeling "fearful," wasstronger in the control room than in the room with plants. Therewereno significant differences between the negative feelingsreported in the plants room and the nonplant objects room.

After the cold pressor wasadministered, therewereno differenceson most ZIPERS items between those tested in the presence of plants compared to the control or nonplant objects rooms (Table 3). O ne exception was for the item "I feel happy or pleased." People continued to feel happier in the presence of plants compared to the other two treatments. In general, however, most of the room treatment effects on

Table 3. Subjects' self-reported emotional states ${ }^{z}$, as measured on the Z uckerman I nventory of Personal R eactions ( $Z$ uckerman, 1977), before and after immersing their hands in ice water in an experimental room with no decorative objects (control) or with nonplant decorative objects compared to states when plants are present.

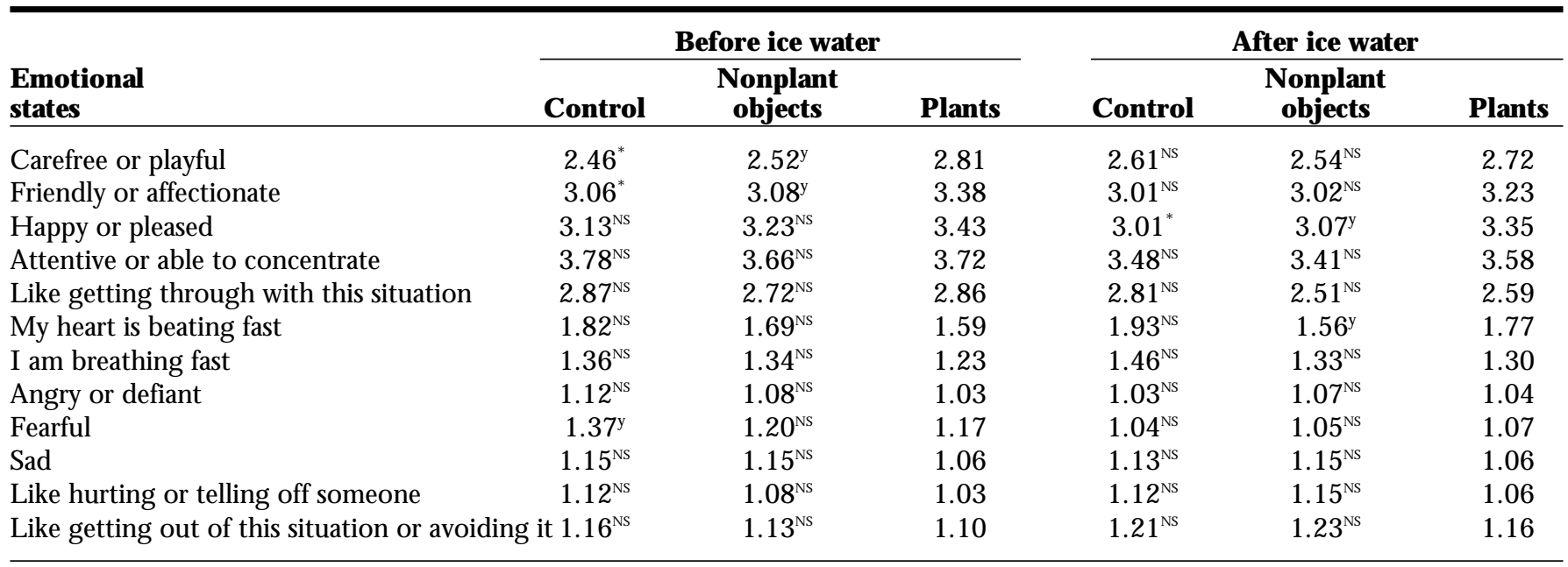

zM eans are based on a scale of 1-5, with 1 being "not at all" and 5 being "very much."

$\mathrm{NS}_{1},{ }^{*}$ Score is nonsignificant (NS) or significantly different from score with plants at $\mathrm{P} \leq 0.10(\mathrm{y})$ or $0.05(*)$, respectively. 


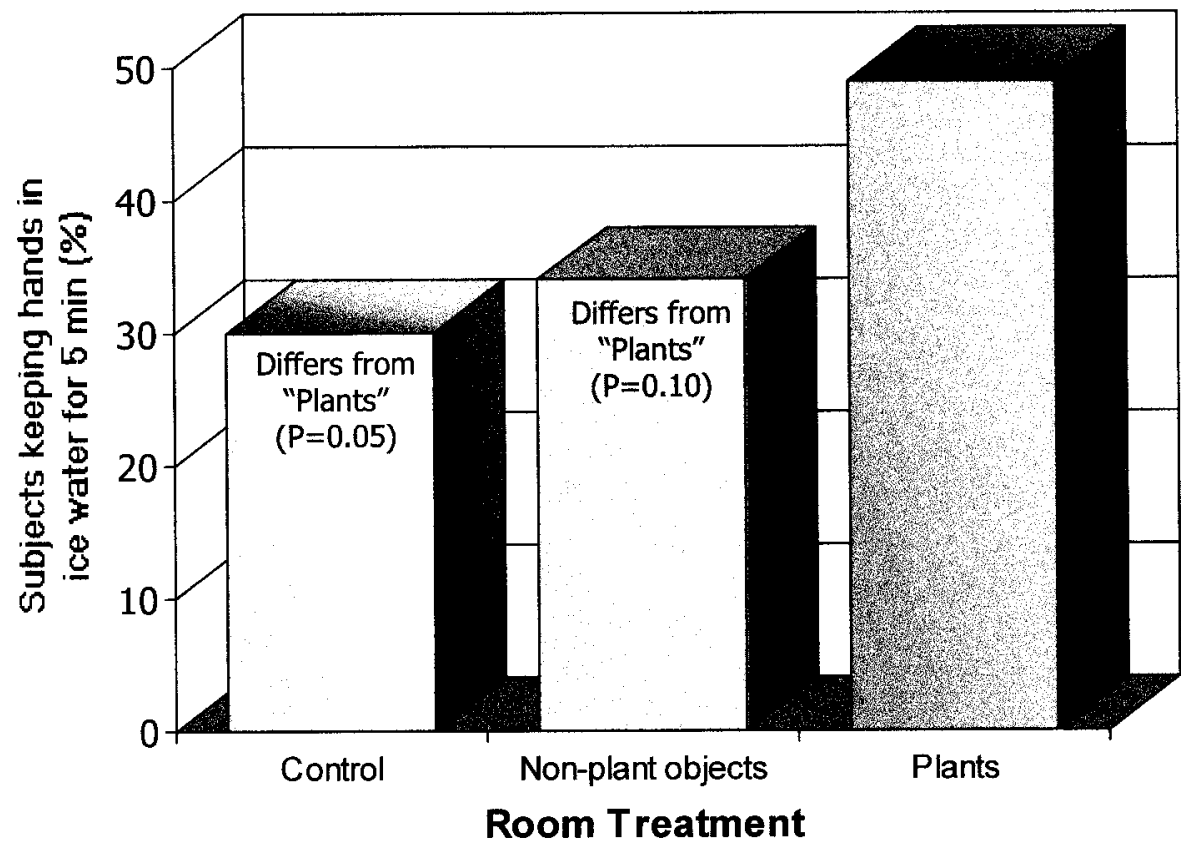

Fig. 2. Percent of subjects in the experimental room with no decorative objects present (control) or with nonplant decorative objects who kept their hands in ice water for 5 min compared to percent who kept their hands submerged for $5 \mathrm{~min}$ with plants present. The proportion of subjects in the control or nonplant objects treatment who kept their hands in ice water for 5 min was compared to the proportion in the plants treatment using a chi-square analysis.

ZIPERS responses appear to diminish over time. This is consistent with the idea that subjects beginning an experiment in aroom without plants are more apprehensive about what will happen than subjects in a room with plants; at the end of the experiment, such apprehension would be gone. Another possible explanation is that the discomfort experienced during the ice water bath may havehad a moderating effect on the positive emotional responses produced when plants were present.

Pain tolerance. The proportion of subjects who kept their hands in ice water for $5 \mathrm{~min}$ (the maximum allowable time) was significantly larger in the room with plantsthan the proportion in the control room (Fig. 2). Subjects in the room with plants were able to tolerate the cold pressor longer than subjects in the control treatment, and, therefore, exhibited a higher level of pain tolerance. This is consistent with U Irich's report (1984) of patientsneeding fewer doses of strong medication to recover from surgery when in hospital rooms with a view of trees than when in rooms with a view of a building wall. The proportion of subjects who kept their hands in ice water for 5 min was also significantly higher in the room with plants than the proportion in the nonplant objects room (Fig. 2). This demonstrates that the positive benefits of plants are not simply associated with their decorative value.

Thisresearch indicatesthat people's impressions of a room and their mental well-being can besignificantly improved when plants are added. When people perceive a room as calming and cheerful, their outlook likely will be positive. Thisstudy al so indicates that decorative objects are not as effective as plants in improving people's perceptions of a room. Further studies are needed to fully determine the potential usefulness of incorporating plants in a variety of interior environments to enhance human perceptions of well-being.

This research confirms previous studies documenting the stress-reducing benefits of passively viewing plants. More importantly, it expands earlier research which showed that people tolerate severe pain for a few days after major surgery better in the presence of plants (U Irich, 1984) by demonstrating that peopleal so tolerate short-term discomfort (icy hand for 5 minutes) better in the presence of plants. If people can tolerate various kinds of pain better when plants are present, then, for example, their need for analgesics may be reduced.

\section{Literature cited}

Anderson, J.E. 1987. Assessing affective characteristicsin theschools. Reston Publishers, Reston, Va.

Cimprich, B. 1993. Development of an intervention to restore attention in cancer patients. Cancer N ursing 16(2):83-92.

Conover, W.J. 1980. Practical nonparametric statistics, 2nd ed. Wiley, N ew York, N.Y.

L arsen, L., J. Adams, B. D eal, B. Kweon, and E. Tyler. 1998. Plants in the workplace: the effects of plant density on productivity, attitudes, and perceptions. Environ. Behavior 30:261-281.

Laviana, J.E., R.H . M attson, and F.H . Rohles. 1983. Plantsasenhancers of theindoor environment, p. 738-741. In: A.T. Pope and L.D. $\mathrm{H}$ augh (eds.). Proc. $\mathrm{H}$ uman Factors Soc. 27th Annu. M tg. H uman FactorsSoc., SantaM onica, Calif.

Lohr, V.I., C.H. Pearson-Mims, and G.K. Goodwin. 1996. Interior plants may improve worker productivity and reduce stress in a windowless environment. J. Environ. Hort. 14(2):97-100.

M ooney, P. and P.L. N icell. 1992. The importance of exterior environment for Alzheimer residents: Effective care and risk management. $\mathrm{H}$ ealthcare $\mathrm{M}$ gt. 5:23-29.

M oore, E.O. 1981-82. A prison environment's effect on health care service demands. J. Environ. Systems 11:17-34.

Rohles, F.H. and G.A. M illiken. 1981. A scaling procedure for environmental research, p. 472476. In: R.C. Sugarman (ed.). Proc. H uman Factors Soc. 25th Annu. M tg. H uman Factors Soc., Santa M onica, Calif.

SAS Institute Inc. 1988. SAS/ STAT 7 user's guide, release 6.03 ed. SAS I nstitute Inc., Cary, N.C.

Shoemaker, C.A., K. Randal, P.D. Relf, and E.S. Geller. 1992. Relationships between plants, behavior, and attitudes in an office environment. H ortT echnology 2:205-206.

U Irich, R.S. 1984. View through a window may influence recovery from surgery. Science 224:420-421.

U Irich, R.S. and R. Parsons. 1992. Influences of passive experiences with plants on individual well-being and health, p. 93-105. In: D. Relf (ed.). The role of horticulture in human wellbeing and social development. Timber Press, Portland, O re.

Wolff, B.B. 1986. Behavioral measurement of human pain, p. 121-151. In: R.A. Sternbach (ed.). Thepsychology of pain. Raven Press, $\mathrm{N}$ ew York.

Zuckerman, M . 1977. D evelopment of a situation-specific trait-state test for the prediction and measurement of affective responses. J. Consulting Clinical Psychol. 45:513-523. 